Вісник Харківського національного університету імені В.Н. Каразіна Серія "Математика, прикладна математика і механіка" Том 89,2019 , с. $76-92$

УДК 517.977
Visnyk of V.N.Karazin Kharkiv National University Ser. "Mathematics, Applied Mathematics and Mechanics"

Vol. 89, 2019, p. 76-92

DOI: $10.26565 / 2221-5646-2019-89-06$

\title{
Time-optimal control problem with two final points for a kinematic model of an UAV
}

\author{
S.Yu. Ignatovich, Yu.V. Sukhinina \\ V.N. Karazin Kharkiv National University, Kharkiv, 4 Svobody sqr., 61022, \\ Ukraine \\ ignatovich@ukr.net,julitvs@gmail.com
}

We study the time-optimal control problem for an unmanned aerial vehicle (drone) moving in the plane of a constant altitude; a kinematic model is considered where the angular velocity is a control. The drone must reach a given unit circle in the minimal possible time and stay on this circle rotating clockwise or counterclockwise. We obtain a complete solution of this time-optimal control problem and give a solution of the optimal synthesis problem.

Keywords: a kinematic model; time-optimal control problem; optimal synthesis

Ігнатович С.Ю., Сухініна Ю.В. Задача швидкодії з двома кінцевими точками для кінематичної моделі БПЛА. Ми досліджуємо задачу швидкодії для безпілотного літального апарату (дрону), що рухається у площині на сталій висоті; розглядається кінематична модель, в якій керуванням $\epsilon$ кутова швидкість. Дрон має досягти заданого одиничного кола за найменший можливий час і залишитись на цьому колі, обертаючись за або проти годинникової стрілки. Ми отримуємо повний розв'язок цієї задачі швидкодії і даємо розв'язок задачі оптимального синтезу.

Ключові слова: кінематична модель; задача швидкодії; оптимальний синтез

Игнатович С.Ю., Сухинина Ю.В. Задача быстродействия с двумя конечными точками для кинематической модели БПЛА. Мы исследуем задачу быстродействия для беспилотного летательного аппарата (дрона), который движется в плоскости на постоянной высоте; рассматривается кинематическая модель, в которой управлением является угловая скорость. Дрон должен достичь заданной единичной окружности за наименьшее возможное время и остаться на ней, вращаясь по или против часовой стрелки. Мы получаем полное решение этой задачи быстродействия и даем решение задачи оптимального синтеза.

Ключевые слова: кинематическая модель; задача быстродействия; оптимальный синтез

2010 Mathematics Subject Classification 49N35; 93C10.

\section{Introduction}

In the papers [1], [2], a kinematic model of an unmanned aerial vehicle (drone) moving at a constant altitude was considered. In particular, for this model, the time-optimal control problem was studied, where the angular velocity is a control parameter.

(c) S. Yu. Ignatovich, Yu. V.Sukhinina, 2019 
Though the drone moves in the space, under the condition of a constant altitude its motion can be considered in a plane. Let $(x, y) \in \mathbb{R}^{2}$ be its coordinates in the plane and let $\theta$ be the angle between the direction of the drone motion and the $x$-axis. We assume that the drone speed is equal to 1 and that the drone can rotate right and left with the angular velocity $|u(t)| \leq 1$. From the kinematic point of view, such a flying is determined by the Markov-Dubins equations [3], [4]. Taking into account the speed constraints and accepting the time optimality requirements, we obtain the following optimal control problem:

$$
\begin{gathered}
\left\{\begin{array}{l}
\dot{x}=\cos \theta, \\
\dot{y}=\sin \theta, \\
\dot{\theta}=u,
\end{array}\right. \\
(x, y) \in \mathbb{R}^{2}, \theta \in \mathbb{S}^{1}, \quad u=u(t) \in[-1,1], 0 \leq t \leq T, \\
x(0)=x_{0}, y(0)=y_{0}, \theta(0)=\theta_{0}, x(T)=x_{T}, y(T)=y_{T}, \theta(T)=\theta_{T}, \\
T \rightarrow \min .
\end{gathered}
$$

In the papers [1], [2], instead of fixing the final point $(x(T), y(T), \theta(T))$, similar problems were considered under the following final conditions: a drone steers to the circle of radius 1 centered at the origin and then moves along this circle counterclockwise (the final time $T$ is the moment of hitting the circle). As shown in [1], these final conditions allow reducing the problem (1); below we recall this simplification.

Let us choose new variables $(\widetilde{x}, \widetilde{y})$ of the form

$$
\left(\begin{array}{l}
\widetilde{x} \\
\widetilde{y}
\end{array}\right)=\left(\begin{array}{cc}
\cos \theta & \sin \theta \\
-\sin \theta & \cos \theta
\end{array}\right)\left(\begin{array}{l}
x \\
y
\end{array}\right)
$$

Then

$$
\begin{gathered}
\dot{\widetilde{x}}=\cos ^{2} \theta-x \cdot u \cdot \sin \theta+\sin ^{2} \theta+y \cdot u \cdot \cos \theta=1+u \cdot \widetilde{y} \\
\dot{\widetilde{y}}=-\cos \theta \cdot \sin \theta-x \cdot u \cdot \cos \theta+\cos \theta \cdot \sin \theta-y \cdot u \cdot \sin \theta=-u \cdot \widetilde{x}
\end{gathered}
$$

hence, the initial system becomes bilinear:

$$
\left\{\begin{array}{l}
\dot{\tilde{x}}=+u \cdot \widetilde{y}+1, \\
\dot{\widetilde{y}}=-u \cdot \widetilde{x}, \\
\dot{\theta}=u .
\end{array}\right.
$$

Now, let us analyze the final conditions. For $t=T$, the drone is on the unit circle, hence,

$$
\left\{\begin{array}{l}
x(T)=\cos \tau, \\
y(T)=\sin \tau
\end{array}\right.
$$

for some $\tau \in[0,2 \pi)$. At this moment its velocity $(\dot{x}(T), \dot{y}(T))=(\cos \theta(T), \sin \theta(T))$ is tangent to the unit circle and it moves counterclockwise, hence, $\theta(T)=\tau+\frac{\pi}{2}$. 
Substituting this expression to (4) we get

$$
\left\{\begin{array}{l}
x(T)=\cos \left(\theta(T)-\frac{\pi}{2}\right)=\sin \theta(T) \\
y(T)=\sin \left(\theta(T)-\frac{\pi}{2}\right)=-\cos \theta(T) .
\end{array}\right.
$$

Now, taking into account (2) we obtain

$$
\left\{\begin{array}{l}
\widetilde{x}(T)=\sin \theta(T) \cdot \cos \theta(T)-\cos \theta(T) \cdot \sin \theta(T)=0, \\
\widetilde{y}(T)=-\sin \theta(T) \cdot \sin \theta(T)-\cos \theta(T) \cdot \cos \theta(T)=-1 .
\end{array}\right.
$$

Hence, the final condition $(\widetilde{x}(T), \widetilde{y}(T))=(0,-1)$ does not include $\theta(T)$.

Thus, one simplifies the problem and obtains the two-dimensional timeoptimal control problem in the variables $(\widetilde{x}(t), \widetilde{y}(t))$. Below we omit the tilde symbol; then the obtained problem is

$$
\begin{gathered}
\left\{\begin{array}{l}
\dot{x}=u \cdot y+1, \\
\dot{y}=-u \cdot x,
\end{array}\right. \\
u=u(t) \in[-1,1], 0 \leq t \leq T, \quad x(0)=x_{0}, y(0)=y_{0}, \quad T \rightarrow \min ,
\end{gathered}
$$

with the final conditions

$$
x(T)=0, \quad y(T)=-1 .
$$

The existence of a solution follows from the Filippov Theorem [5].

The symmetric time-optimal control problem can be considered, when a drone moves along the unit circle clockwise; in this case the final conditions are

$$
x(T)=0, \quad y(T)=1 .
$$

Such problems were thoroughly studied in [1], [2].

In the present paper we consider a natural variation of the problem. We suppose that both directions of motion along the final circle are allowed. This corresponds to the time-optimal control problem (7) with two endpoints $(0,-1)$ or $(0,1)$ :

$$
x(T)=0, \quad y(T)= \pm 1 ;
$$

the final point is chosen for reasons of minimizing the time of movement.

\section{Optimal trajectories}

Below we distinguish trajectories that are optimal in the sense of the problem with two final points (7), (10) (we call them "optimal") and trajectories that are optimal in the sense of the problem with one final point $(7),(8)$ or $(7),(9)$ (we call them "( $0,-1)$-optimal" or "( 0,1$)$-optimal" respectively).

Obviously, any optimal trajectory ending at $(0,1)$ is $(0,1)$-optimal and any optimal trajectory ending at $(0,-1)$ is $(0,-1)$-optimal, however, in general, the converse is not true. 
First, we study properties of $(0,1)$-optimal and $(0,-1)$-optimal trajectories. In essence, these results are obtained in [1], [2]; we discuss them for the sake of completeness.

Let us make use of the Pontryagin Maximum Principle [6]. In our case the Hamilton-Pontryagin function has the form

$$
H=\psi_{1} \cdot(u \cdot y+1)+\psi_{2} \cdot(-u \cdot x)=u \cdot\left(\psi_{1} \cdot y-\psi_{2} \cdot x\right)+\psi_{1} .
$$

Let us consider a $(0,1)$-optimal or a $(0,-1)$-optimal control $\widehat{u}(t)$; let $T$ be the optimal time. Denote by $(\widehat{x}(t), \widehat{y}(t))$ the corresponding optimal trajectory. Due to the Pontryagin Maximum Principle, there exists a number $\lambda \geq 0$ and a nontrivial solution of the dual system

$$
\left\{\begin{array}{l}
\dot{\psi}_{1}=\widehat{u}(t) \cdot \psi_{2} \\
\dot{\psi}_{2}=-\widehat{u}(t) \cdot \psi_{1}
\end{array}\right.
$$

such that

$$
\begin{gathered}
\widehat{u}(t)=\operatorname{sign}(\phi(t)) \text { for } t \in[0, T] \text { such that } \phi(t) \neq 0, \\
|\phi(t)|+\psi_{1}(t)-\lambda=0, \quad t \in[0, T],
\end{gathered}
$$

where $\phi(t)$ is a switching function,

$$
\phi(t)=\psi_{1}(t) \cdot \widehat{y}(t)-\psi_{2}(t) \cdot \widehat{x}(t) .
$$

In particular, (14) implies

$$
\psi_{1}(t) \leq \lambda, \quad t \in[0, T]
$$

Let us note that

$$
\begin{gathered}
\dot{\phi}=\dot{\psi}_{1} \cdot \widehat{y}+\psi_{1} \cdot \dot{\hat{y}}-\dot{\psi}_{2} \cdot \widehat{x}-\psi_{2} \cdot \dot{\widehat{x}}= \\
=u \cdot \psi_{2} \cdot \widehat{y}-\psi_{1} \cdot u \cdot \widehat{x}+u \cdot \psi_{1} \cdot \widehat{x}-\psi_{2} \cdot u \cdot \widehat{y}-\psi_{2}=-\psi_{2},
\end{gathered}
$$

that is,

$$
\dot{\phi}(t)=-\psi_{2}(t) .
$$

Concerning the dual system (12), we notice that it includes the optimal control $\widehat{u}(t)$, so, it cannot be solved without knowing $\widehat{u}(t)$. However, let us consider, how the variables $\psi_{1}$ and $\psi_{2}$ depend on each other. We easily get $\frac{d}{d t}\left(\psi_{1}^{2}+\psi_{2}^{2}\right)=0$, hence, $\psi_{1}^{2}(t)+\psi_{2}^{2}(t)$ is a (nonzero) constant. Without loss of generality we assume

$$
\psi_{1}^{2}(t)+\psi_{2}^{2}(t) \equiv 1
$$

that is, a point $\left(\psi_{1}(t), \psi_{2}(t)\right)$ moves along the unit circle. 


\section{Singular and nonsingular optimal trajectories}

First, we assume that $\lambda>0$.

If $\phi(t) \neq 0$, then the optimal control $\widehat{u}(t)$ takes the values 1 or -1 . If $\widehat{u}(t)=1$, then the trajectory $(\widehat{x}(t), \widehat{y}(t))$ goes clockwise along a circle centered at $(0,-1)$, while if $\widehat{u}(t)=-1$, then the trajectory $(\widehat{x}(t), \widehat{y}(t))$ goes counterclockwise along a circle centered at $(0,1)$ (Fig. 1$)$. In particular, if the final point is $(0,1)$, then $\widehat{u}(t)=1$ on the last piece of the trajectory and if the final point is $(0,-1)$, then $\widehat{u}(t)=-1$ on the last piece of the trajectory.

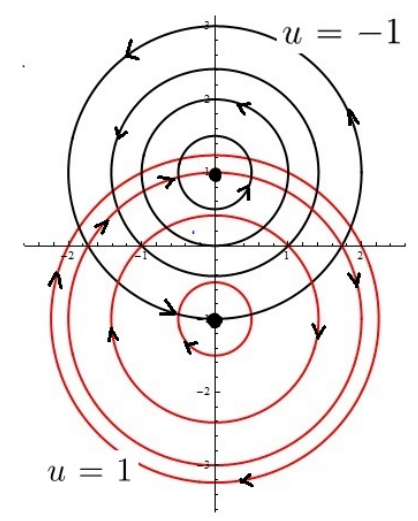

Fig. 1. Nonsingular trajectories

Let us consider the time moment $t_{0}$ when the control switches from $u=1$ to $u=-1$ or vice versa ("switching point"). Then $\phi\left(t_{0}\right)=0$, therefore, (14) gives $\psi_{1}\left(t_{0}\right)=\lambda \geq 0$. If the optimal trajectory contains several switching points, $\psi_{1}$ takes the same value at any of them. On the other hand, if $|\widehat{u}(t)|=1$, then the point $\left(\psi_{1}(t), \psi_{2}(t)\right)$ goes along the unit circle with the unit speed in the positive direction if $\widehat{u}(t)=-1$ and in the negative direction if $\widehat{u}(t)=1$. Hence, the time intervals between switchings are of the same duration. Moreover, it follows from (16) that the point $\left(\psi_{1}(t), \psi_{2}(t)\right)$ moves within the longer arc between the switching points $\left(\lambda, \sqrt{1-\lambda^{2}}\right)$ and $\left(\lambda,-\sqrt{1-\lambda^{2}}\right)$, hence, the duration between switching moments is greater than $\pi$ (Fig. 2). Hence, any optimal trajectory contains a finite number of switchings.

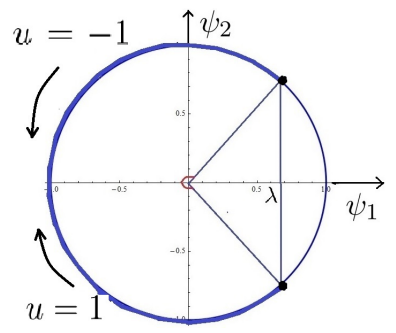

Fig. 2. Dual variable 
If $\lambda=1$, then the duration between two switchings should equal $2 \pi$. This means that the optimal trajectory $(\widehat{x}(t), \widehat{y}(t))$ contains a whole circle, what contradicts the time optimality of this trajectory. Hence, if a trajectory has at least two switching points, then $\lambda<1$.

It follows from (15) that, at the end time moment, $|\phi(T)|=\left|\psi_{1}(T)\right|$; hence, (14) implies $\left|\psi_{1}(T)\right|+\psi_{1}(T)=\lambda$. Since $\lambda>0$, we get $\psi_{1}(T)>0$ and then $\psi_{1}(T)=\frac{1}{2} \lambda$. This implies that the duration of the last piece of the optimal trajectory is less than the duration between two switchings.

Now let us suppose that the optimal trajectory has a singular piece, that is, there exists an interval $\left(t_{1}, t_{2}\right)$ where $\phi(t) \equiv 0, t \in\left(t_{1}, t_{2}\right)$. Then (17) implies that $\psi_{2}(t) \equiv 0, t \in\left(t_{1}, t_{2}\right)$. Therefore, (14) and (18) give $\psi_{1}(t) \equiv \lambda$ on $\left(t_{1}, t_{2}\right)$ and therefore $\lambda=1$. Then from (15) it follows that $\widehat{y}(t) \equiv 0$. Finally, from (7) we get $\dot{\hat{x}}(t) \equiv 1$, i.e., the trajectory goes along the line $y=0$ in the positive direction with the unit speed (Fig. 3).

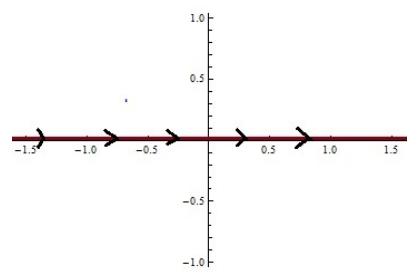

Fig. 3. Singular trajectories

Thus, $\lambda=1$. Taking into account the previous arguments we see that if the trajectory has a singular piece, then it has neither other singular pieces nor switchings from $u=1$ to $u=-1$ or vice versa. Therefore, such a trajectory has one or two switchings: one from $u= \pm 1$ to $u=0$ (possibly) and one from $u=0$ to $u= \pm 1$ (necessarily).

Finally, consider the case $\lambda=0$.

Suppose that such a trajectory has a singular piece, i.e., $\phi(t) \equiv 0, t \in\left(t_{1}, t_{2}\right)$, then (14) and (17) imply $\psi_{1}(t) \equiv 0$ and $\psi_{2}(t) \equiv 0, t \in\left(t_{1}, t_{2}\right)$, what is impossible.

Hence, a trajectory has no singular pieces. Suppose it has at least one switching point. For example, let the final point be $(0,1)$ (the case $(0,-1)$ can be treated analogously). If $t_{0}$ is the moment of the last switching, then $\phi\left(t_{0}\right)=0$. Then (14), (15), (18) imply $\widehat{x}\left(t_{0}\right)=0$. This means that the last switching (from $u=-1$ to $u=1)$ is at the point $(0,-3)$. Let us consider a piece of this trajectory preceding this switching; this is an arc of the circle of radius 4 centered at $(0,1)$. Let us consider a point $\left(x_{1}, y_{1}\right)$ on this arc (which differs from $\left.(0,-3)\right)$; then

$$
x_{1}=-4 \sin \xi, \quad y_{1}=1-4 \cos \xi,
$$

for some $\xi>0$. The time of motion from the point $\left(x_{1}, y_{1}\right)$ to the final point $(0,1)$ equals $T(\xi)=\xi+\pi$.

Now let us consider a trajectory from $\left(x_{1}, y_{1}\right)$ having a singular piece. Namely, $u(t)=1$ until the trajectory reaches the line $y=0$; then $u(t)=0$ until $x(t)$ 
becomes $-\sqrt{3}$; finally $u(t)=1$. The first piece of such a trajectory is an arc of the circle centered at $(0,-1)$ of radius

$$
r=\sqrt{x_{1}^{2}+\left(y_{1}+1\right)^{2}}=\sqrt{20-16 \cos \xi}
$$

Then

$$
x_{1}=-r \sin \tau, \quad y_{1}=-1-r \cos \tau,
$$

where $\tau=\arcsin \left(-\frac{x_{1}}{r}\right)=\arcsin \left(\frac{4 \sin \xi}{r}\right)>0$. Suppose this trajectory reaches the line $y=0$ at the point $\left(x_{2}, y_{2}\right)=\left(x_{2}, 0\right)$, then

$$
x_{2}=-r \sin \varphi, \quad y_{2}=0=-1-r \cos \varphi
$$

for some $\varphi>0$. Hence, $\varphi=\arccos \left(-\frac{1}{r}\right)$ and $x_{2}=-r \sin \varphi=-\sqrt{r^{2}-1}$, and the time of motion from $\left(x_{1}, y_{1}\right)$ to $\left(x_{2}, 0\right)$ equals $\varphi-\tau$. Obviously, the times of motion from $\left(x_{2}, 0\right)$ to $(-\sqrt{3}, 0)$ (with $\left.u=0\right)$ and from $(-\sqrt{3}, 0)$ to $(0,1)$ (with $u=1)$ equal $-\sqrt{3}-x_{2}$ and $\frac{\pi}{3}$ respectively. Therefore, the time of motion from the point $\left(x_{1}, y_{1}\right)$ to the final point $(0,1)$ along this trajectory equals

$$
\begin{gathered}
T_{1}(\xi)=(\varphi-\tau)+\left(-\sqrt{3}-x_{2}\right)+\frac{\pi}{3}= \\
=\arccos \left(-\frac{1}{\sqrt{20-16 \cos \xi}}\right)-\arcsin \left(\frac{4 \sin \xi}{\sqrt{20-16 \cos \xi}}\right)-\sqrt{3}+\sqrt{19-16 \cos \xi}+\frac{\pi}{3} .
\end{gathered}
$$

Obviously, for $\xi=0$ we get $T(0)=T_{1}(0)=\pi$.

If $\xi$ increases, $T(\xi)$ also increases. For $T_{1}(\xi)$, evaluating its derivative at $\xi=0$ we get $\left.\frac{d}{d \xi} T_{1}(\xi)\right|_{\xi=0}=-2$. Hence, $T_{1}(\xi)$ decreases as $\xi$ increases. This means that for (small) $\xi>0$

$$
T_{1}(\xi)<T(\xi)
$$

therefore, the trajectory from $\left(x_{1}, y_{1}\right)$ through the point $(0,-3)$ is not optimal.

Hence, $\lambda=0$ can correspond to the $(0,1)$-optimal or $(0,-1)$-optimal trajectories without switchings entirely contained in the left semi-circles of radius 2 centered at $(0,-1)$ or at $(0,1)$. For all other $(0,1)$-optimal and $(0,-1)$-optimal trajectories we have $\lambda>0$.

Summarizing, we obtain that there can exist two types of $(0,1)$-optimal or $(0,-1)$-optimal trajectories:

- Singular trajectories, which contain one singular piece $\widehat{u}(t) \equiv 0$ and have no more than two switchings (from $u=0$ to $u= \pm 1$ and, maybe, from $u= \pm 1$ to $u=0)$. In particular, the point of the last switching is $(-\sqrt{3}, 0)$ and the duration of the last piece equals $\frac{\pi}{3}$.

- Nonsingular trajectories, where the control takes the values \pm 1 . If such a trajectory has more than one switching, then the time intervals between switchings are of the same duration (greater than $\pi$ ), the first piece can be the same or shorter, and the last piece is shorter. 


\section{Duration of the last piece of an optimal trajectory}

Now we return to the time-optimal control problem with two final points (7), (10) and study properties of optimal trajectories. Recall that each optimal trajectory is a $(0,1)$-optimal or a $(0,-1)$-optimal trajectory, i.e., it is of the form described above.

Let us consider a nonsingular optimal trajectory $(\widehat{x}(t), \widehat{y}(t))$ ending at $(\widehat{x}(T), \widehat{y}(T))=(0,1)$ and suppose it has at least one switching (then $\lambda>0)$. Denote by $\left(x_{1}, y_{1}\right)=\left(\widehat{x}\left(t_{1}\right), \widehat{y}\left(t_{1}\right)\right)$ the point of the last switching; it belongs to the circle of radius 2 centered at $(0,-1)$. Now we show that $T-t_{1} \leq \frac{\pi}{3}$.

Suppose the contrary, i.e., $T-t_{1}>\frac{\pi}{3}$, then the point $\left(\widehat{x}\left(t_{0}\right), \widehat{y}\left(t_{0}\right)\right)=(-\sqrt{3}, 0)$ lies on the trajectory, where $t_{0}=T-\frac{\pi}{3}$, and moreover $t_{0}>t_{1}$. Let us consider the curve $(\widehat{x}(t),|\widehat{y}(t)|)$. Obviously, it is also a trajectory of the system (7). Moreover, it ends at the point $(0,1)$ at the same time $T$ and has at least one switching more than the initial trajectory; in particular, $\left(x_{1},\left|y_{1}\right|\right)$ and $(-\sqrt{3}, 0)$ are its switching points.

Suppose $(\widehat{x}(t),|\widehat{y}(t)|)$ is $(0,1)$-optimal. Since its last switching point is $\left(\widehat{x}\left(t_{0}\right),\left|\widehat{y}\left(t_{0}\right)\right|\right)=(-\sqrt{3}, 0)$, the duration of the last piece equals $\frac{\pi}{3}$. As was shown in the previous section, $\psi_{1}\left(t_{0}\right)=\lambda$ and $\psi_{1}(T)=\frac{\lambda}{2}$. Therefore, $T-t_{0}=\frac{\pi}{3}=$ $\arccos \left(\frac{\lambda}{2}\right)-\arccos (\lambda)$, what implies $\lambda=1$. Hence, this trajectory has no other switchings, what contradicts our construction.

Therefore, $(\widehat{x}(t),|\widehat{y}(t)|)$ is not $(0,1)$-optimal. Hence, there exists a $(0,1)$ optimal trajectory $\left(x^{0}(t), y^{0}(t)\right)$ starting at the point $(\widehat{x}(0),|\widehat{y}(0)|)$ and ending at $(0,1)$ in the time $T^{0}<T$.

If $\widehat{y}(0) \geq 0$, the obtained fact contradicts the optimality of the initial trajectory $(\widehat{x}(t), \widehat{y}(t))$.

If $\widehat{y}(0)<0$, let us consider the symmetric trajectory $\left(x^{0}(t),-y^{0}(t)\right)$. It starts at the point $(\widehat{x}(0), \widehat{y}(0))$ and ends at $(0,-1)$ in the time $T^{0}<T$, what contradicts the optimality of $(\widehat{x}(t), \widehat{y}(t))$.

Hence, $T-t_{1} \leq \frac{\pi}{3}$. For an optimal trajectory ending at $(\widehat{x}(T), \widehat{y}(T))=(0,-1)$, the arguments are the same.

Thus, in any case the duration of the last piece of the optimal trajectory is no greater than $\frac{\pi}{3}$.

\section{Switching curve}

Let us consider a nonsingular optimal trajectory ending at $(\widehat{x}(T), \widehat{y}(T)=(0,1)$ and suppose it has at least two switchings. Denote by $\left(x_{1}, y_{1}\right)$ the point of the last switching. Arguments given above yield that the duration of the last piece of the trajectory is no greater than $\frac{\pi}{3}$, hence, $\left(x_{1}, y_{1}\right)$ belongs to the circle of radius 2 centered at $(0,-1)$ and $0 \leq y_{1}<1, x_{1}<0$. We suppose that $y_{1}>0$ (the case $y_{1}=0$ is noted below).

We are interested in the point of the preceding switching; denote it by $(x, y)$. Obviously, the points $\left(x_{1}, y_{1}\right)$ and $(x, y)$ are located at the same circle centered at $(0,1)$. 
If $y_{1}=y$, then the point $(x, y)$ belongs to the circle of radius 2 centered at $(0,-1)$; hence, the preceding piece of this trajectory goes along this circle. Let us consider any point $\left(x_{2}, y_{2}\right)$ on this piece which is located on the upper arc of the mentioned circle between the points $\left(x_{1}, y_{1}\right)$ and $(x, y)$; without loss of generality assume $x_{2}>0$. Obviously, there exists a control which steers $\left(x_{2}, y_{2}\right)$ to $(0,1)$ faster than through the points $(x, y)$ and $\left(x_{1}, y_{1}\right)$ : namely, $u=-1$ until the trajectory again crosses the mentioned circle, and then $u=1$. This contradicts the optimality of the initial trajectory.

Hence, $y_{1} \neq y$. The switching function $\phi$ equals zero and $\psi_{1}$ equals $\lambda$ at both time moments of switching, while $\psi_{2}$ equals $\sqrt{1-\lambda^{2}}$ at one of them and $-\sqrt{1-\lambda^{2}}$ at the other. Hence, (15) implies

$$
\frac{x_{1}}{y_{1}}=-\frac{x}{y}
$$

Then we have the following relations between $\left(x_{1}, y_{1}\right)$ and $(x, y)$ :

$$
\left\{\begin{array}{l}
x_{1}^{2}+\left(y_{1}+1\right)^{2}=4, \\
x_{1}^{2}+\left(y_{1}-1\right)^{2}=x^{2}+(y-1)^{2}, \\
\frac{x_{1}}{y_{1}}=-\frac{x}{y} .
\end{array}\right.
$$

Our goal is to express $x$ via $y$. Denote $\frac{x}{y}=c>0$. Substituting $x=c y$ and $x_{1}=-c y_{1}$ to the second equation of (19) gives

$$
\left(c^{2}+1\right) y_{1}^{2}-2 y_{1}=\left(c^{2}+1\right) y^{2}-2 y .
$$

Denoting $a=c^{2}+1$ and taking into account that $y_{1} \neq y$ we obtain

$$
a\left(y_{1}+y\right)=2,
$$

hence, $y_{1}=\frac{2}{a}-y$. Substituting $x_{1}=-c y_{1}$ and $y_{1}=\frac{2}{a}-y$ to the first equation of (19) we get

$$
a\left(\frac{2}{a}-y\right)^{2}+2\left(\frac{2}{a}-y\right)=3,
$$

what gives

$$
a^{2} y^{2}-(6 y+3) a+8=0 .
$$

Solving this equation w.r.t. $a$, we get

$$
a=\frac{6 y+3-\sqrt{4 y^{2}+36 y+9}}{2 y^{2}}=\frac{1}{y^{2}}\left(3 y+\frac{3}{2}-\sqrt{y^{2}+9 y+\frac{9}{4}}\right)
$$

(the sign "-" is chosen since $a y<2$ due to $(20)$ ). However, $x=c y=\sqrt{a-1} y$. Substituting the expression for $a$ from (21), we obtain the description of the switching curve:

$$
x=\sqrt{-y^{2}+3 y+\frac{3}{2}-\sqrt{y^{2}+9 y+\frac{9}{4}}}, \quad y \in(0,1) .
$$


As a limit case, the values $y=0$ and $y=1$ correspond to $x=0$.

Notice that for all points $\left(x_{1}, y_{1}\right)$ such that $x_{1}^{2}+\left(y_{1}-1\right)^{2}>1$ there is no preceding switching point in the upper semi-plane; this concerns also the point $(-\sqrt{3}, 0)$. In the next section we show that such optimal trajectories have only one switching.

For all points $\left(x_{1}, y_{1}\right)$ such that $x_{1}^{2}+\left(y_{1}-1\right)^{2} \leq 1$ there exists a unique point $(x, y)$ satisfying $(22)$; if the optimal trajectory contains this point and also contains some preceding piece, it necessarily has a switching at $(x, y)$.

Considering analogously the case of optimal trajectories ending at $(0,-1)$ we obtain the complete description of the switching curve

$$
x=\sqrt{-y^{2}+3|y|+\frac{3}{2}-\sqrt{y^{2}+9|y|+\frac{9}{4}}}, \quad y \in[-1,1] .
$$

Since a duration of any interval between two switchings is no less than $\pi$, we get that any nonsingular optimal trajectory has no more than two switchings in the semi-plane where the final point lies.

\section{Optimal trajectories (may) lie entirely in one semi-plane}

We now apply arguments close to those used in Section 3. Let us consider an optimal trajectory $(\widehat{x}(t), \widehat{y}(t))$; suppose it ends at $(\widehat{x}(T), \widehat{y}(T))=(0,1)$. Suppose $(\widehat{x}(t), \widehat{y}(t))$ passes through the point $\left(\widehat{x}\left(t_{0}\right), \widehat{y}\left(t_{0}\right)\right)$ with $\widehat{y}\left(t_{0}\right)=0$ so that $\widehat{y}(t)$ changes its sign. Suppose also that this trajectory has at least one switching.

Let us consider the curve $(\widehat{x}(t),|\widehat{y}(t)|)$. It is a trajectory of the system $(7)$ and ends at the point $(0,1)$ in the same time $T$. Suppose $(\widehat{x}(t),|\widehat{y}(t)|)$ is $(0,1)$-optimal.

First suppose $\widehat{x}\left(t_{0}\right) \neq 0$, then $\left(\widehat{x}\left(t_{0}\right), \widehat{y}\left(t_{0}\right)\right)=\left(\widehat{x}\left(t_{0}\right), 0\right)$ is a switching point of $(\widehat{x}(t),|\widehat{y}(t)|)$. Since $\phi\left(t_{0}\right)=0$ and $\widehat{y}\left(t_{0}\right)=0,(15)$ gives $\psi_{2}\left(t_{0}\right) \widehat{x}\left(t_{0}\right)=0$. Since $\widehat{x}\left(t_{0}\right) \neq 0$, we obtain $\psi_{2}\left(t_{0}\right)=0$. Then $\psi_{1}\left(t_{0}\right)=1$, therefore, $\lambda=1$ and the optimal trajectory $(\widehat{x}(t),|\widehat{y}(t)|)$ cannot have other switchings, what gives a contradiction.

Now suppose $\widehat{x}\left(t_{0}\right)=\widehat{y}\left(t_{0}\right)=0$, then the curve $(\widehat{x}(t),|\widehat{y}(t)|)$ for $t \in\left[t_{0}, T\right]$ consists of the arc of the circle of radius 1 centered at $(0,1)$ and the arc of the circle of radius 2 centered at $(0,-1)$. However, as was shown above, if this trajectory is $(0,1)$-optimal, it should have a switching at the point $(0,0)$ whereas the curve $(\widehat{x}(t),|\widehat{y}(t)|)$ for $t \in\left[t_{0}-\varepsilon, t_{0}\right]$ for small $\varepsilon>0$ belongs to the circle of radius 1 centered at $(0,1)$ and, therefore, has no switching at $(0,0)$.

Thus, $(\widehat{x}(t),|\widehat{y}(t)|)$ is not $(0,1)$-optimal. Hence, there exists a $(0,1)$-optimal trajectory $\left(x^{0}(t), y^{0}(t)\right)$ starting at the point $(\widehat{x}(0),|\widehat{y}(0)|)$ and ending at $(0,1)$ in the time $T^{0}<T$.

If $\widehat{y}(0) \geq 0$, the obtained fact contradicts the optimality of $(\widehat{x}(t), \widehat{y}(t))$.

If $\widehat{y}(0)<0$, let us consider the symmetric trajectory $\left(x^{0}(t),-y^{0}(t)\right)$. It starts at the point $(\widehat{x}(0), \widehat{y}(0))$ and ends at $(0,-1)$ in the time $T^{0}<T$, what contradicts the optimality of $(\widehat{x}(t), \widehat{y}(t))$.

For an optimal trajectory which ends at $(0,-1)$, the arguments are the same.

Therefore, we get that any nonsingular optimal trajectory having at least one switching lies completely in one semi-plane $y \geq 0$ or $y \leq 0$ and, moreover, has no 
more than two switchings.

Now let us consider an optimal trajectory without switchings; suppose it ends at $(0,1)$. Then it belongs to the circle of radius 2 centered at $(0,-1)$. If it fills more than a half of this circle and $y(0)>0$, the arguments given above (with the trajectory $(\widehat{x}(t),|\widehat{y}(t)|))$ yield a contradiction. Hence, this trajectory crosses over the line $y=0$ no more than once. Analogous result holds for an optimal trajectory without switchings ending at $(0,-1)$.

Finally, notice that if an optimal trajectory $(\widehat{x}(t), \widehat{y}(t))$ without switchings passes through the line $y=0$, it can be substituted by the optimal trajectory $(\widehat{x}(t),|\widehat{y}(t)|)$ or $(\widehat{x}(t),-|\widehat{y}(t)|)$ (depending on the sign of $\widehat{y}(0)$ ), which lies completely in one semi-plane. The same is true for singular trajectories.

Thus, in any case one can choose an optimal trajectory which lies completely in one semi-plane $y \geq 0$ or $y \leq 0$.

\section{Optimal synthesis}

Now we describe the optimal control as a function of $(x, y) \neq(0, \pm 1)$ (Fig. 4).

(i) Let $y \neq 0$. Then $u(x, y)=-\operatorname{sign}(y)$ if

$$
-\sqrt{-y^{2}-2|y|+3} \leq x<\sqrt{-y^{2}+3|y|+\frac{3}{2}-\sqrt{y^{2}+9|y|+\frac{9}{4}}}
$$

and $u(x, y)=\operatorname{sign}(y)$ otherwise. (This condition implies that $u(x, y)=-\operatorname{sign}(y)$ if $|y| \geq 1$.)

(ii) Let $y=0$. Then $u(x, y)=0$ iff $x<-\sqrt{3}$; otherwise $u(x, y)$ can equal 1 or -1 .

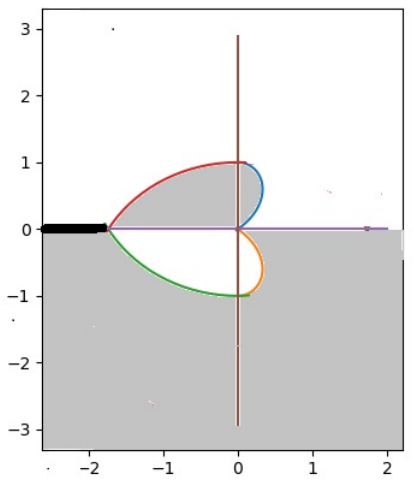

Fig. 4. Optimal synthesis: $u=0$ (black), $u=-1$ (white), $u=1$ (grey)

Finally, let us summarize the solution of the optimal control problem with two final points (7), (10).

First, suppose $y_{0} \neq 0$. For all starting points satisfying the condition

$$
x_{0}^{2}+\left(y_{0}+\operatorname{sign}\left(y_{0}\right)\right)^{2}>4
$$


the optimal control is singular. Namely, $u(t)=-\operatorname{sign}\left(y_{0}\right)$ until the trajectory reaches the line $y=0$; then $u(t)=0$ until $x(t)$ becomes $-\sqrt{3}$; finally $u(t)=1$ or $u(t)=-1$. If

$$
x_{0}^{2}+\left(y_{0}+\operatorname{sign}\left(y_{0}\right)\right)^{2}=4,
$$

the optimal control has one switching: $u(t)=-\operatorname{sign}\left(y_{0}\right)$ until the trajectory reaches the line $y=0$; then $u(t)=1$ or $u(t)=-1$.

Hence, for each such starting point there exist two optimal controls which differs by the sign on the last piece of the trajectory.

For all other points the control is nonsingular and has no more than two switchings; moreover, it is unique. Namely, if (24), (25) do not hold and

$$
-\sqrt{-y_{0}^{2}-2\left|y_{0}\right|+3}<x_{0}<\sqrt{-y_{0}^{2}+3\left|y_{0}\right|+\frac{3}{2}-\sqrt{y_{0}^{2}+9\left|y_{0}\right|+\frac{9}{4}}}
$$

then $u(t)=\operatorname{sign}\left(y_{0}\right)$ until the trajectory reaches the switching curve $(23)$; then $u(t)=-\operatorname{sign}\left(y_{0}\right)$ until the trajectory reaches the circle of radius 2 centered at $\left(0,-\operatorname{sign}\left(y_{0}\right)\right)$; finally $u(t)=\operatorname{sign}\left(y_{0}\right)$. If

$$
x_{0}=-\sqrt{-y_{0}^{2}-2\left|y_{0}\right|+3}
$$

then $u(t)=\operatorname{sign}\left(y_{0}\right)$ has no switchings. If $(24)-(27)$ do not hold, then $u(t)=-\operatorname{sign}\left(y_{0}\right)$ until the trajectory reaches the circle of radius 2 centered at $\left(0,-\operatorname{sign}\left(y_{0}\right)\right)$; then $u(t)=\operatorname{sign}\left(y_{0}\right)$.

Now suppose $y_{0}=0$.

If $x_{0}<-\sqrt{3}$, then $u(t)=0$ until $x(t)$ becomes $-\sqrt{3}$; then $u(t)=1$ or $u(t)=-1$. If $x_{0}=-\sqrt{3}$, then the trajectory has no switchings, $u(t)=1$ or $u(t)=-1$.

If $-\sqrt{3}<x_{0}<0$, then $u(t)=u_{0}= \pm 1$ until the trajectory reaches the switching curve $(23)$; then $u(t)=-\operatorname{sign}\left(u_{0}\right)$ until the trajectory reaches the circle of radius 2 centered at $\left(0,-\operatorname{sign}\left(u_{0}\right)\right)$; finally $u(t)=\operatorname{sign}\left(u_{0}\right)$ (the final point is $\left.\left(0, u_{0}\right)\right)$.

If $0 \leq x_{0}<\sqrt{3}$, then $u(t)=u_{0}= \pm 1$ until the trajectory reaches the circle of radius 2 centered at $\left(0, \operatorname{sign}\left(u_{0}\right)\right)$; finally $u(t)=-\operatorname{sign}\left(u_{0}\right)$ (the final point is $\left.\left(0,-u_{0}\right)\right)$. If $x_{0}=\sqrt{3}$, then $u(t)=u_{0}= \pm 1$ until the trajectory reaches the line $y=0$; then $u(t)=1$ or $u(t)=-1$.

If $x_{0}>\sqrt{3}$, then $u(t)= \pm 1$ until the trajectory reaches the line $y=0$; then $u(t)=0$ until $x(t)$ becomes $-\sqrt{3}$; then $u(t)=1$ or $u(t)=-1$.

Hence, for all starting points satisfying $y_{0}=0$ there exist two or four (if $x_{0} \geq \sqrt{3}$ ) optimal controls.

\section{Examples}

Example 1. Consider the time-optimal control problem

$$
\left\{\begin{array}{l}
\dot{x}=u \cdot y+1, \\
\dot{y}=-u \cdot x,
\end{array}\right.
$$

$u \in[-1,1], 0 \leq t \leq T, x(0)=4, x(T)=0, y(0)=4, y(T)= \pm 1$. 
Checking the condition (24) we get that the optimal control is singular; since $y(0)>0$ we get

$$
u(t)= \begin{cases}-1, & t \in\left[0, \tau_{1}\right) \\ 0, & t \in\left[\tau_{1}, \tau_{2}\right), \\ \pm 1, & t \in\left[\tau_{2}, T\right]\end{cases}
$$

where $y\left(\tau_{1}\right)=0$ and $T-\tau_{2}=\frac{\pi}{3}$. Hence, for $t \in\left[0, \tau_{1}\right]$ we get

$$
\left\{\begin{array}{l}
x(t)=a_{1} \cdot \cos t+a_{2} \cdot \sin t \\
y(t)=a_{1} \cdot \sin t-a_{2} \cdot \cos t+1 .
\end{array}\right.
$$

Substituting $x(0)=4, y(0)=4, y\left(\tau_{1}\right)=0$ we obtain $a_{1}=4, a_{2}=-3$, $\tau_{1}=\pi+\arcsin \left(\frac{1}{5}\right)-\arcsin \left(\frac{3}{5}\right) \approx 2.6994, x\left(\tau_{1}\right)=-\sqrt{24} \approx-4.8990$ (here and below we keep four digits after comma). For $t \in\left[\tau_{1}, \tau_{2}\right]$ we get

$$
\left\{\begin{array}{l}
x(t)=t+x\left(\tau_{1}\right)-\tau_{1}, \\
y(t)=0
\end{array}\right.
$$

Since $x\left(\tau_{2}\right)=\tau_{2}+x\left(\tau_{1}\right)-\tau_{1}=-\sqrt{3}$, we get $\tau_{2}=-\sqrt{3}+\sqrt{24}+\tau_{1} \approx 5.8664$. Finally, for $t \in\left[\tau_{2}, T\right]$ where $T=\tau_{2}+\frac{\pi}{3} \approx 6.9136$ we get

$$
\left\{\begin{array}{l}
x(t)=b_{1} \cdot \cos t+b_{2} \cdot \sin t \\
y(t)= \pm\left(-b_{1} \cdot \sin t+b_{2} \cdot \cos t-1\right),
\end{array}\right.
$$

where the sign \pm corresponds to the choice $u=1$ or $u=-1$ for the last piece of the trajectory. Substituting $x\left(\tau_{2}\right)=-\sqrt{3}, y\left(\tau_{2}\right)=0$ we finally obtain $b_{1}=-2 \sin \left(\tau_{2}+\frac{\pi}{3}\right) \approx-1.1789, b_{2}=2 \cos \left(\tau_{2}+\frac{\pi}{3}\right) \approx 1.6156$.

We conclude that the optimal controls (28) with $u=1$ and $u=-1$ on the last piece steer the system from the initial point $(4,4)$ to the end-point $(0,1)$ or $(0,-1)$ respectively in the same time $T=-\sqrt{3}+\sqrt{24}+\pi+\arcsin \left(\frac{1}{5}\right)-\arcsin \left(\frac{3}{5}\right)+\frac{\pi}{3} \approx$ 6.9136. The obtained trajectories are drawn in Fig. 5.
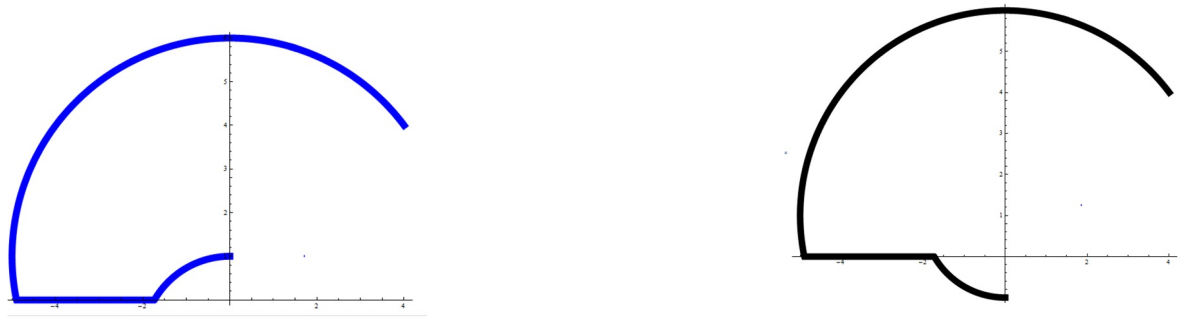

Fig. 5. Two optimal trajectories, $(x(0), y(0))=(4,4)$

Example 2. Consider the time optimal control problem

$$
\begin{aligned}
& \left\{\begin{array}{l}
\dot{x}=u \cdot y+1, \\
\dot{y}=-u \cdot x,
\end{array}\right. \\
& u \in[-1,1], 0 \leq t \leq T, x(0)=-0.53, x(T)=0, y(0)=0.31, y(T)= \pm 1 \text {. }
\end{aligned}
$$


Checking the condition (24) we get that the optimal control is nonsingular, i.e., it takes the values \pm 1 only. Since $y(0)>0$, the final point is $(0,1)$.

First, let us try to find an admissible control with one switching,

$$
u(t)= \begin{cases}-1, & t \in[0, \tau), \\ 1, & t \in[\tau, T]\end{cases}
$$

Substituting such a control to the system and using the initial and final conditions, we obtain the admissible trajectory ending at $(0,1)$ (up to four digits after comma)

$$
\begin{aligned}
& \left\{\begin{array}{l}
x(t)=-0.53 \cdot \cos t+0.69 \cdot \sin t, \\
y(t)=-0.53 \cdot \sin t-0.69 \cdot \cos t+1,
\end{array} \quad t \in[0,5.5867),\right. \\
& \left\{\begin{array}{l}
x=0.5103 \cdot \cos t+1.9338 \cdot \sin t, \\
y=-0.5103 \cdot \sin t+1.9338 \cdot \cos t-1,
\end{array} \quad t \in[5.5867,6.0252] ;\right.
\end{aligned}
$$

i.e., the time of steering to the origin equals $T \approx 6.0252$ (Fig. 6 ).

However, the given initial point satisfies the condition (26). Hence, the control (29) is not optimal; the optimal control has two switchings, i.e., has the form

$$
u(t)= \begin{cases}1, & t \in\left[0, \tau_{1}\right), \\ -1, & t \in\left[\tau_{1}, \tau_{2}\right), \\ 1, & t \in\left[\tau_{2}, T\right] .\end{cases}
$$

In order to find $\tau_{1}$ we use the fact that the point $\left(x\left(\tau_{1}\right), y\left(\tau_{1}\right)\right)$ satisfies the condition (23). For $t \in\left[0, \tau_{1}\right]$ we have the trajectory

$$
\left\{\begin{array}{l}
x(t)=-0.53 \cos t+1.31 \sin t \\
y(t)=0.53 \sin t+1.31 \cos t-1 .
\end{array}\right.
$$

Then the condition (23) implies $\tau_{1} \approx 0.5921$. Hence, for $t \in\left[0, \tau_{1}\right]$ we have

$$
\left\{\begin{array}{l}
x(t)=b_{1} \cdot \cos t+b_{2} \cdot \sin t \\
y(t)=b_{1} \cdot \sin t-b_{2} \cdot \cos t+1
\end{array}\right.
$$

where $b_{1} \approx-0.1027, b_{2} \approx 0.6748$. Taking into account that the point $\left(x\left(\tau_{2}\right), y\left(\tau_{2}\right)\right)$ belongs to the circle of radius 2 centered at $(0,-1)$, we get $\tau_{2} \approx 5.0349$. Finally, for $t \in\left[\tau_{2}, T\right]$ we obtain

$$
\left\{\begin{array}{l}
x(t)=c_{1} \cos t+c_{2} \sin t \\
y(t)=-c_{1} \sin t+c_{2} \cos t-1,
\end{array}\right.
$$

where $c_{1} \approx 1.5732, c_{2} \approx 1.2349$ and, therefore, the trajectory steers to the end point $(0,1)$ at the time $T \approx 5.3779$. The optimal trajectory is drawn in Fig. 7 . 


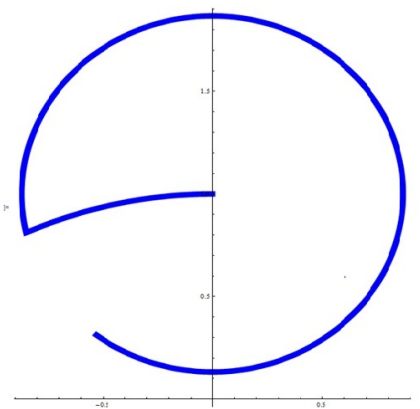

Fig. 6. Admissible trajectory, $T \approx 6.0252$

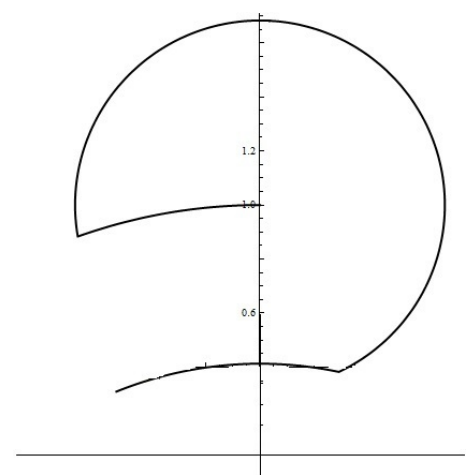

Fig. 7. Optimal trajectory, $T \approx 5.3779$

\section{ORCID ID}

S. Yu. Ignatovich (iD https://orcid.org/0000-0003-2272-8644

Yu. V.Sukhinina (iD https://orcid.org/0000-0002-1001-9675

\section{REFERENCES}

1. T. Maillot, U. Boscain, J.-P. Gauthier, U. Serres. Lyapunov and minimum-time path planning for drones, J. Dyn. Control Syst. - 2015. - 1. V.21. - P. 47-80.

2. M.A. Lagache, U. Serres, V. Andrieu. Minimal time synthesis for a kinematic drone model, Mathematical Control and Related Fields. - 2017. - 2. V.7. - P. 259-288.

3. A.A. Markov. Some examples of the solution of a special kind of problem in greatest and least quantities (Russian), Communications of Kharkov Mathematical Society. - 1889. - V.1. - P. 250-276.

4. L.E. Dubins. On curves of minimal length with a constraint on average curvature and with prescribed initial and terminal positions and tangents, American Journal of Mathematics. - 1957. - V.79. P. 497-516.

5. A.F. Filippov. On some questions in the theory of optimal regulation (Russian), Vestnik Moskov. Univ. Ser. Mat. Mec. Astr. Fiz. Him. - 1959. - 2. - P. 25-32.

6. L.S. Pontryagin, V.G. Boltyanskii, R.V. Gamkrelidze, E.F. Mishchenko. Mathematical theory of optimal processes. 1961. Nauka, Moscow, 391 p.; Engl. transl.: John Wiley \& Sons, Inc., New York-London, 1962.

Ігнатович С.Ю., Сухініна Ю.В. Задача швидкодії з двома кінцевими точками для кінематичної моделі БПЛА. Ми досліджуємо задачу швидкодії для безпілотного літального апарату (дрону), що рухається у площині на сталій висоті. Розглядається кінематична модель, в якій керуванням є кутова швидкість. Така 
система описується рівняннями Маркова-Дубінса; розв'язанню різних задач оптимального і допустимого керування і стабілізації для подібних моделей присвячена велика кількість робіт. У статтях [T. Maillot, U. Boscain, J.-P. Gauthier, U. Serres, Lyapunov and minimum-time path planning for drones, J. Dyn. Control Syst., V. 21 (2015)] та [M.A. Lagache, U. Serres, V. Andrieu, Minimal time synthesis for a kinematic drone model, Mathematical Control and Related Fields, V. 7 (2017)] розв'язується задача швидкодії, в якій дрон має досягти заданого одиничного кола за найменший можливий час і залишитись на цьому колі, обертаючись проти годинникової стрілки. У вказаних роботах, зокрема, показано, що в цьому випадку задача спрощується, а саме, стає двовимірною. У даній роботі ми розглядаємо природне узагальнення вказаної постановки: в нашій задачі дрон має досягти заданого одиничного кола за найменший можливий час і залишитись на ньому, але при цьому обидва напрямки обертання є допустимими. Тобто дрон може обертатися за годинниковою стрілкою або проти годинникової стрілки, а напрямок обертання обирається з міркувань мінімізації часу руху. Таке переформулювання приводить до задачі оптимальної швидкодії з двома кінцевими точками. У статті ми отримуємо повний розв'язок цієї задачі швидкодії. Зокрема, ми показуємо, що оптимальне керування набуває значень \pm 1 або 0 і має не більше двох перемикань. Якщо оптимальне керування є сингулярним, тобто містить ділянку $u=0$, то така ділянка $\epsilon$ єдиною, а тривалість останньої ділянки дорівнює $\pi / 3$; більш того, в цьому випадку оптимальне керування неєдине, а кінцева точка може бути як $(0,1)$, так і $(0,-1)$. Якщо ж оптимальне керування $€$ несингулярним, тобто набуває значень \pm 1 , то воно єдине (за винятком випадку, коли тривалість останньої ділянки дорівнює $\pi / 3$ ), а оптимальна траєкторія цілком міститься у верхній або в нижній полуплощині. Також ми даємо розв'язок задачі оптимального синтезу.

Ключові слова: кінематична модель; задача швидкодії; оптимальний синтез.

S. Yu. Ignatovich, Yu. V Sukhinina. Time-optimal control problem with two final points for a kinematic model of an UAV. We study the time-optimal control problem for an unmanned aerial vehicle (drone) moving in the plane of a constant altitude. A kinematic model is considered where the angular velocity is a control. Such a system is described by Markov-Dubins equations; a large number of works are devoted to solving different optimal and admissible control and stabilization problems for such models. In the papers [T. Maillot, U. Boscain, J.-P. Gauthier, U. Serres, Lyapunov and minimum-time path planning for drones, J. Dyn. Control Syst., V. 21 (2015)] and [M.A. Lagache, U. Serres, V. Andrieu, Minimal time synthesis for a kinematic drone model, Mathematical Control and Related Fields, V. 7 (2017)] the time optimal control problem is solved where the drone must reach a given unit circle in the minimal possible time and stay on this circle rotating counterclockwise. In particular, in the mentioned works it is shown that is this case the problem is simplified; namely, the problem becomes two-dimensional. In the present paper we consider a natural generalization of the formulation mentioned above: in our problem, the drone must reach a given unit circle in the minimal possible time and stay on this circle, however, both rotating directions are admissible. That is, the drone can rotate clockwise or counterclockwise; the direction is chosen for reasons of minimizing the time of movement. Such a reformulation leads to the time-optimal control problem with two final points. In the paper, we obtain a complete solution of this time-optimal control problem. In particular, we show that the optimal control takes the values \pm 1 or 0 and has no more than two switchings. If the optimal control is singular, i.e., contains a piece $u=0$, then this piece is unique and the duration of the last piece equals $\pi / 3$; moreover, in this case the optimal control ins non-unique and 
the final point can be $(0,1)$ as well as $(0,-1)$. If the optimal control is non-singular, i.e., takes the values \pm 1 , then it is unique (except the case when the duration of the last piece equals $\pi / 3$ ) and the optimal trajectory entirely lies in the upper or lower semi-plane. Also, we give a solution of the optimal synthesis problem.

Keywords: a kinematic model; time-optimal control problem; optimal synthesis.

Article history: Received: 1 April 2019;

Accepted:18 May 2019. 